\title{
Introducing the capstone initiative: building pracademic capacity in Canada's community safety \& well-being sector
}

\author{
Cal Corley*
}

Many people within the community safety well-being sector undertaking advanced education (e.g., MA, MBA, MPA) struggle landing on a thesis topic (or in the case of an MBA, their final project) that will meaningfully inform the future of community safety and well-being.

Recently, a friend approached me to discuss his proposed topic - the importance of physical fitness in 21st century policing. Okay, I thought — interesting perhaps, but surely not impactful on the future policing and community safety. As important as this topic might be, has it not already been covered extensively over the years? And besides, will it be of interest to others five to ten years from now? So after discussing other options, he has decided to focus on something much better aligned with the future of community safety, or as Gretzky put it, "... where the puck is going to be".

A pracademic is an individual who is recognized as an expert in his or her field, who also possesses sound academic training (Huey \& Mitchell, 2016). Developing greater pracademic capacity within the community safety and well-being sector is not just nice to do, but an essential ingredient to the future transformations taking place across Canada. In one respect, it is a matter of supply and demand. Increasing demand for evidence-based solutions and applied research exceeds the supply of skilled and interested academic researchers, according to Anthony Braga (Braga, 2016) in a recent article.

It is against this backdrop that CSKA and its partners - the Centre for Collaborative Justice Studies (University of Regina), the Forensic Centre for Behavioural Science and Justice Studies (University of Saskatchewan), and the Canadian Society for Evidence-based Policing — are pleased to launch the Capstone Initiative.

Capstone focuses on supporting community safety and well-being leaders and practitioners who are engaged in advanced education (e.g., MA, MBA, MPA, MSc). The initiative will support interested learners within the sector in five (5) interconnected ways:

1. Assisting learners identify thesis/project topics that are relevant and meaningful to the future of community safety and well-being;

2. Providing mentorship and connecting learners to national and international experts and resources;
3. Providing a forum (e.g., annual symposium) at which participants can present their thesis/project and engage in a moderated discussion with top experts, senior officials, and civil society leaders;

4. Providing the opportunity for interested learners to publish their work in CSKA's Journal of Community Safety and Well-Being; and

5. Providing coaching for those who would like to publish but feel they need some support.

We also welcome those who have completed an advanced degree within the last three (3) years and are interested in publishing their research (i.e., elements 4 and 5 above).

In its inaugural year, Capstone will focus primarily on those working in Saskatchewan's community safety and well-being sector who are engaged in advanced studies. This includes those working in related community-based organizations. Depending on demand, we may be able to extend participation to others outside of Saskatchewan in this first year as well - and to that end, we encourage those who may be interested to reach out to us.

If you are interested in participating, or would like additional information, please contact the author (ccorley@ cskacanada.ca) or Shannon Fraser-Hansen at CSKA, either by email (sfraserhansen@cskacanada.ca) or phone: 306384-2751. For more information on CSKA or its flagship Journal of Community Safety and Well-Being, please visit www.cskacanada.ca

CONFLICT OF INTEREST DISCLOSURES

The author has no conflicts of interest connected to the submission of this article.

AUTHOR AFFILIATIONS

${ }^{*}$ Community Safety Knowledge Alliance, Saskatoon, SK, Canada.

\section{REFERENCES}

Braga, A. A. (2016). The value of 'pracademics' in enhancing crime analysis in police departments. Policing: AJournal of Policy and Practice, 10(3), 308-314.

Huey, L., \& Mitchell, R.J. (2016). Unearthing hidden keys: why pracademics are an invaluable (if underutilized) resource in policing research. Policing: A Journal of Policy and Practice, 10(3), 300-307. 